\section{As representações sobre o alcoolismo em uma associação de ex-bebedores: os Alcoólicos Anônimos}

\author{
Representations of alcoholism in a former \\ alcoholics' association: Alcoholics Anonymous
}

Edemilson Antunes de Campos 1

\title{
Apresentação
}

1 Programa de Pós-graduação em Ciências Sociais, Universidade Federal de São Carlos,

São Carlos, Brasil.

Correspondência E. A. Campos Av. Angélica 439, apto. 3B, São Paulo, SP 01227-000, Brasil. edicampos21@hotmail.com edi_veri@terra.com.br

\section{Abstract}

This article is designed to review the representations of alcoholism provided by members of an association of former alcoholics, namely Alcoholics Anonymous (AA), based on partial results from a qualitative survey conducted in the Sapopemba group of AA in a neighborhood on the outskirts of the city of São Paulo, Brazil. The article thus analyzes alcoholism from an emic perspective, i.e., how it is conceived and managed by those who acknowledge themselves as being "sick as alcoholics", how they explain the sickness, how they experience it, and how they endeavor to overcome it. The purpose is to present $A A$ and its treatment strategy and to highlight the link made by the association by conceiving of alcoholism as a physical, moral, and spiritual illness.

Alcoholic Anonymous; Alcoholism; Self-Help Groups
O objetivo deste artigo é analisar as representações formuladas pelos membros da associação de ex-bebedores Alcoólicos Anônimos (AA) sobre o álcool e o alcoolismo, com base nos resultados parciais da pesquisa realizada no grupo Sapopemba de AA, em bairro da periferia da cidade de São Paulo, Brasil.

O alcoolismo é um dos mais sérios problemas de saúde pública na atualidade, despertando a atenção de autoridades médicas e sanitárias em diversos países. Na França, por exemplo, país conhecido pela grande produção e exportação de bebidas alcoólicas, um estudo conduzido pelo Instituto Nacional da Saúde e da Pesquisa Médica (INSERM) aponta que, apesar do consumo global de álcool ter diminuído $40,0 \%$ nos últimos quarenta anos, cerca de $8,6 \%$ da população francesa com idade entre 12 e 75 anos têm algum problema relacionado ao álcool, o que totaliza aproximadamente cinco milhões de pessoas, entre as quais dois milhões são dependentes do álcool 1. Já nos Estados Unidos, estudos epidemiológicos apontam para uma prevalência da dependência do álcool que atinge cerca de $15,0 \%$ da população na faixa etária de 15 a 54 anos 1 .

No Brasil, as cifras também são alarmantes. Segundo os dados do I Levantamento Domiciliar sobre o Uso de Drogas no Brasil 2, realizado em 1999, pelo Centro Brasileiro de Informações 
sobre Drogas Psicotrópicas (CEBRID), da Universidade Federal de São Paulo (UNIFESP), em conjunto com a Secretaria Nacional Anti-drogas (SENAD), a prevalência da dependência do álcool é de $11,2 \%$ na população brasileira, e a maior taxa de dependentes está na população cuja faixa etária é a de 18 a 24 anos.

Nesse cenário, os AA desempenham um papel fundamental, constituindo-se numa importante estratégia terapêutica para o alcoolismo. Os AA são, de acordo com sua literatura oficial composta pelo livro básico de AA, folders de divulgação e também pela revista $V i$ vência, de publicação trimestral, "uma irmandade de homens e mulheres que compartilham suas experiências, forças e esperanças, a fim de resolver seu problema comum e ajudar outros a se recuperarem do alcoolismo" 3 (p. 2). Trata-se de um programa de recuperação, expresso nos “doze passos e doze tradições" 4, cujo objetivo é ajudar os alcoólicos a evitar o "primeiro gole" e, assim, a manter a sua sobriedade.

A irmandade dos AA nasceu em 1935, em Akron, Estado de Ohio, nos Estados Unidos, após uma conversa entre um corretor da Bolsa de Nova York e um médico de Akron, conhecidos, respectivamente, como Bill Wilson e Bob Smith. Eles constataram que, por alguma razão até ali não bem compreendida, conseguiam ficar sem beber durante bons períodos depois que passavam algum tempo conversando e compartilhando seus problemas. Após passar por uma verdadeira "experiência espiritual" e experimentar "fortes sentimentos de triunfo, paz e serenidade", segundo depoimento do próprio corretor, ele decidiu trabalhar para que outros alcoólicos se beneficiassem com a descoberta; ele viu que, ao falar para outros alcoólicos, "sentia-se revitalizado", conseguindo manter-se sóbrio.

Desde então, o AA teve uma rápida expansão em escala mundial, fazendo parte do itinerário terapêutico de milhares de pessoas em todo mundo. Segundo Gabhainn 5, o número de membros da irmandade em todo mundo tem crescido em progressão geométrica, tendo passado de 100 membros, em 1940, para 476 mil, em 1980; para 653 mil, em 1983 e para 979 mil, em 1990. Em 2002, estimava-se que o número de grupos de AA em todo mundo fosse de 100.103, totalizando 2.215.293 membros, segundo dados do Escritório Mundial de Alcoólicos Anônimos. No Brasil, o primeiro grupo de AA surgiu em 1947 e, atualmente, há cerca de 5.700 grupos, perfazendo um total de praticamente 120 mil membros, segundo dados do Escritório de Serviços Gerais de Alcoólicos Anônimos.
A eficácia do modelo construído pelos AA para a recuperação do alcoolismo é reconhecida mundialmente, o que fez de AA uma espécie de "grandparent" dos grupos de mútua ajuda 6 , influenciando a constituição de grupos destinados ao tratamento de outras patologias, tais como: Narcóticos Anônimos, Comedores Compulsivos Anônimos, Dependentes de Amor e Sexo Anônimos, Neuróticos Anônimos, Jogadores Anônimos etc.

Todavia, se é certa a prevalência do problema do alcoolismo nos dias atuais, notadamente na sociedade brasileira, ainda são raros os trabalhos, no âmbito das ciências sociais, que se ocupam tanto com o uso "patológico" de bebidas alcoólicas 7 quanto com as estratégias terapêuticas utilizadas pelos membros dos AA para dar conta da "doença alcoólica", mesmo sendo conhecido o fato de que, como lembra Soares 8 (p. 15), “o Brasil é um dos países com maior número de grupos de AA no mundo". Como sublinha Neves 7 , nas ciências sociais o alcoolismo aparece, em geral, como tema tangencial em estudos preocupados com a compreensão das formas e maneiras de beber, de modo que o ato de beber aparece como um ato social, sinalizando para os contextos possíveis, nos quais o uso do álcool é valorizado, operando como uma espécie de "lubrificante social" 7, favorecendo a construção de espaços de sociabilidade. É importante ressaltar, contudo, os esforços empreendidos nos últimos anos em programas de pósgraduação de vários institutos vinculados a universidades brasileiras, com o intuito de preencher essa lacuna por meio do estímulo a pesquisas focalizadas na equação alcoolismo/doença e, sobretudo, na atuação dos grupos de AA 9,10,11.

Nessa perspectiva, este artigo busca compreender os mecanismos colocados em prática pelos membros dos AA para lutar contra o alcoolismo e, assim, legitimar, ao mesmo tempo, sua condição de "doente alcoólico" e sua necessidade de abstinência em relação ao álcool. O problema do alcoolismo é abordado a partir de uma perspectiva êmica, isto é, tal como ele é pensado e gerido por aqueles que se reconhecem como "doentes alcoólicos", notadamente os membros da associação de ex-bebedores AA. Trata-se, portanto, de compreender como os membros de AA abordam o alcoolismo, como eles o explicam, o vivenciam e tentam superálo, a partir de uma concepção do alcoolismo como uma doença físico-moral e espiritual.

Foi fundamental para o estudo a participação, ao longo de 12 meses (entre setembro de 2001 a setembro de 2002), em reuniões de recuperação (abertas), além de outras atividades promovidas pelo grupo Sapopemba de AA, tais 
como: reuniões de entregas de fichas; reuniões de serviços; reuniões de unidade; reuniões temáticas; festas de aniversário do grupo de AA etc. Com isso pode-se compreender o modo como as representações construídas em torno do alcoolismo e de si mesmo como "doente alcoólico", se articulam e orientam as práticas dos membros da associação na luta contra a “doença alcoólica”.

\section{A reunião de recuperação de Alcoólicos Anônimos}

Vinte horas. Ao som de uma campainha, tocada por um membro de AA, que nesse dia ocupa o papel de coordenador, tem início mais uma reunião de recuperação do grupo Sapopemba de AA, localizado na Avenida Vila Ema, em bairro da periferia da cidade de São Paulo. Em uma pequena sala alugada e mantida pelas contribuições dos membros da irmandade, o que é motivo de satisfação para todos, pois evidencia a conquista da auto-suficiência do grupo, reúnem-se todos os dias das 20:00 às 22:00 homens e mulheres, com o objetivo de se apoiarem mutuamente para "evitar o primeiro gole" $\mathrm{e}$ "manter a sobriedade", conforme o relato de seus membros.

A reunião de recuperação é o momento no qual homens e mulheres, membros de AA, compartilham suas experiências individuais histórias de vida do tempo de alcoolismo ativo e da recuperação -, falam também de seus conflitos, perdas e conquistas, atualizando os princípios que presidem o programa de recuperação de AA. Trata-se, portanto, de um momento no qual a doutrina se faz ato; em que a "teoria" e a "prática" se unem para celebrar os princípios inscritos no programa de AA.

A sala onde transcorre a reunião de recuperação do grupo Sapopemba de AA é um ambiente "sóbrio". As paredes são todas "decoradas" com quadros e objetos pertencentes à irmandade. Ali encontramos dois quadros com os Doze Passos e as Doze Tradições de Alcoólicos Anônimos, um quadro-negro com a agenda de atividades do mês corrente, um mural de aviso com notícias do Escritório de Serviço Gerais de AA e vários cartazes com dizeres que, além de darem as boas-vindas aos novatos, estimulam os membros do grupo a continuar sua recuperação, mantendo a sobriedade: "Foi bom você ter vindo"; "Evite o primeiro gole"; "Só por hoje"; "Vá com calma, mas vá”; "Mais participação, melhor recuperação"; "Sem honestidade, não há sobriedade"; "Viva e deixe viver" e "O silêncio faz parte da nossa recuperação”.
Do lado oposto à entrada da sala, encontrase a mesa do coordenador da reunião, responsável por relacionar os nomes e chamar cada membro para fazer sua partilha, marcando o tempo de cada fala, zelando para que todos os inscritos possam trocar suas experiências. $\mathrm{Na}$ mesa do coordenador encontram-se expostos alguns livros da literatura de AA, uma tabuleta indicando aos presentes se a reunião é aberta ou fechada, a sacola que será passada durante a reunião para recolher as contribuições do grupo e uma caixa com fichas de cores diferentes, que são utilizadas para serem distribuídas a um provável ingressante no grupo presente à reunião. Essa ficha dada ao novato marca sua entrada no grupo e reforça seu pertencimento à irmandade.

Sobre a mesa do coordenador encontra-se uma bandeira do grupo Sapopemba de AA, com o símbolo da irmandade: um triângulo com um círculo ao meio, onde está escrita a sigla: AA. Em cada lado do triângulo encontramos inscrito os legados de AA: Recuperação, Unidade e Serviço.

Ao lado da mesa do coordenador encontrase a "cadeira". Assim é chamado o assento em que deve sentar-se o membro do grupo durante sua partilha. A posição da cadeira é estratégica, pois ela fica de frente para todos membros, os quais ficam sentados em cadeiras enfileiradas umas atrás das outras, de modo que todos podem ver a face daquele que está partilhando e vice-versa. Com isso, reforça-se a identificação entre os membros do grupo.

Vive-se, assim, o que é descrito pelos membros de AA como "efeito espelho", isto é, a identificação com as histórias e experiências dos outros membros que estão na mesma situação. Uma das manifestações mais importantes dessa identificação se traduz na crença dos AA segundo a qual "somente um alcoólico pode ajudar outro alcoólico a se recuperar”, reforçando o sentido da mútua ajuda praticada pelo AA: “ajudar outro alcoólico a se recuperar é a melhor maneira de eu manter minha própria sobriedade".

Ao iniciar a reunião, o coordenador lê um preâmbulo que apresenta os objetivos da irmandade aos visitantes e, a seguir, convida a todos a ficarem de pé para fazerem a Oração da Serenidade. A partir desse momento, o coordenador chama pelo primeiro nome cada um dos inscritos para fazer suas partilhas, que são ouvidas em silêncio por todos.

A seguir, apresento alguns depoimentos de membros do grupo Sapopemba de AA, colhidos durante as reuniões de recuperação a que tive oportunidade de participar durante a pesquisa de campo: 
"Meu nome é P. e sou um alcoólico em recuperação que freqüenta as reuniões para deixar de ser bêbado. Para deixar de ser cachaceiro (...). Quando bebia, perdia tudo e deixava de lado a família, os amigos, $o$ trabalho. Com o AA consegui manter minha família, meus amigos. Agora tenho tudo (...). É preciso ter consciência da doença, do que ela causa".

"Meu nome é I., alcoólatra em recuperação, estou no AA há dois meses, perdi minha mulher que se suicidou por causa da bebida (...). Durante a bebedeira eu vivia no fundo do poço; um fundo de poço estreito que me deixava sufocado; eu vivia preso nesse fundo de poço. Com o AA eu consegui chegar à beira desse poço. Quando bebia, eu não via meus filhos, eu não me relacionava com minha mulher. Perdia tudo. Só queria a bebida. Chegava em casa às cinco da tarde e já ia para o boteco. Não comia, vivia para beber. Após, eu percebi que estava perdendo meu segundo casamento também. Cheguei a ficar internado. Quando cheguei no AA estava no fundo do poço e graças ao Poder Superior e a vocês hoje eu tenho tudo. Minha preocupação hoje é com minha família, meu trabalho e com o AA. Beijo meus filhos, minha mulher e estou progredindo. A doença do alcoolismo não me deixava progredir. Meu progresso devo ao Poder Superior e ao grupo de AA".

"Meu nome é A., alcoólatra em recuperação. O AA foi o único lugar em que me falaram que o alcoolismo era uma doença. (...). Depois que eu tomava a primeira e a segunda, eu me transformava naquilo que eu achava que eu era. O alcoolismo leva à morte prematura (...). Em AA não tenho mais vontade de beber. Eu sou um doente alcoólico e não posso beber o primeiro gole”.

"Meu nome é G. e também sou um alcoólatra $e$ venho a essas reuniões para me modificar $e$ parar de beber. Por que com o álcool eu causei muitos problemas assim na família, com meus filhos. O álcool estava me dominando. Eu já tava completamente dominado pelo álcool".

É, portanto, no interior dessa atmosfera que a estratégia terapêutica de AA constrói sua eficácia. As reuniões de recuperação são um poderoso mecanismo para a ritualização dos princípios da associação, possibilitando aos membros de AA construírem, ao mesmo tempo, uma interpretação para seu mal e uma representação de si mesmos como "doentes alcoólicos em recuperação”. É por meio das "práticas ritualizadas" 12 nas reuniões de recuperação, que os membros do grupo podem (re)atualizar o programa de recuperação de AA, comunicando e legitimando sua condição, ao mesmo tempo de “doente alcoólico" e de "alcoólico em recuperação”.
Nas reuniões, o espaço e o tempo atuam como categorias coletivamente construídas, delimitando uma ordem de sentido na qual cada gesto, palavra e atitude desempenham um papel significativo para a concretização de uma verdadeira cultura de recuperação. É essa configuração espaço-temporal que permite aos membros de AA reconhecerem-se como parte de uma cultura regida por valores próprios, que orientam suas práticas em direção à manutenção da sobriedade.

Pode-se dizer que as narrativas feitas durante a reunião de recuperação, embora fundadas na experiência intransferível da dor e do sofrimento, compartilham um código comum e específico para expressar os dilemas e embaraços da prática social, e o confronto cotidiano entre as situações vividas e os valores próprios da vida em sociedade. A experiência do alcoolismo se constrói, portanto, no interior de um campo semântico próprio a uma ordem de sentido, dentro da qual seus conteúdos significativos são construídos, ao mesmo tempo em que se afirma a identidade do "doente alcoólico em recuperação".

Avaliando-se os conteúdos das narrativas citadas é possível explorar a plêiade de significados que recobre a experiência do alcoolismo para os membros de um grupo de AA. Os membros de AA são unânimes em indicar um momento, uma espécie de "limiar do sofrimento" a que chegaram antes de entrarem para a associação. Trata-se do momento descrito, metaforicamente, por eles como "fundo-de-poço". E é a partir de um "déclic" 12, isto é, da tomada de consciência das "perdas" acumuladas durante o tempo do contato com a bebida alcoólica, que o membro de AA se dá conta de que está “dominado pelo álcool”, de que é “incapaz de parar de beber", sendo, portanto, um "dependente da bebida alcoólica”.

Essa situação-limite e derradeira é vivida pelos membros de AA sob a forma de múltiplas perdas: "quando bebia perdia tudo e deixava de lado a família, os amigos, o trabalho"; "quando bebia eu não via meus filhos, eu não me relacionava com minha mulher. Perdia tudo. Só queria a bebida" e do sofrimento que delas decorre.

As metáforas são um importante instrumento discursivo, por meio do qual os indivíduos constróem e expressam suas aflições, permitindo a elaboração de um sentido para suas experiências da doença, estendendo as possibilidades de produção dos significados, a partir de uma inovação semântica 13. A metáfora "fundo-de-poço" é, portanto, central no campo semântico de AA, expressando a decadência física e moral do indivíduo e a situação de limina- 
ridade social em que se encontra, permitindo ao alcoólico uma síntese de seu estado de dependência e o reconhecimento de que "perdeu o controle sobre o álcool”, possibilitando, ao mesmo tempo, a expressão de suas aflições e a elaboração de um sentido para a experiência do alcoolismo. Nesse instante, como dizem os membros de AA, o bebedor sente que é "impotente diante do álcool” e que é necessário procurar ajuda.

A imagem do "fundo-de-poço" marca, então, a passagem do bebedor para um novo universo social: o grupo de AA, portador de valores que possibilitam ao ex-bebedor construir a identidade de "doente alcoólico em recuperação”. A identificação entre os membros do grupo, proporcionada pelo pertencimento a uma nova ordem de sentido, permite a elaboração da identidade de "doente alcoólico em recuperação”, que passa agora a compor o referencial central de uma verdadeira "identidade existencial" 14 , possibilitando a ruptura com o "tempo do alcoolismo ativo" e a reorientação de suas ações em vista da conquista da sobriedade.

\section{O alcoolismo: uma doença entre os domínios físico e moral}

A entrada no grupo de AA introduz o ex-bebedor numa ordem de significados que permite a (re)construção de sua identidade. Os membros de AA reconhecem-se agora como "doentes alcoólicos em recuperação”, em oposição à imagem do "bêbado" e do "cachaceiro" dos tempos do alcoolismo ativo. Como conseqüência, o alcoólico adquire um status de doente, com uma positividade não encontrada na representação do "bêbado" e do "cachaceiro": "meu nome é C., um ex-bêbado e hoje um doente alcoólico em recuperação". A oposição bêbado/doente alcoólico assinala a passagem de uma posição estritamente moral e estigmatizante para uma concepção da “doença” próxima do modelo biomédico, mas que é (re)significada no interior de AA, assumindo uma dimensão propriamente "físico-moral".

Por meio da troca de experiências no interior do grupo, o alcoólico descobre a si mesmo, num universo de iguais. Como explica Marcel Drulhe 15 (p. 322), em seu estudo sobre mulheres alcoólicas e os grupos de ex-bebedores: " $c a$ da uma se reconhece na biografia das outras, $e$ isso favorece a descoberta de um elemento parcial, mas fundamental de sua identidade: o estigma agora escondido do alcoolismo".

Aquele que era estigmatizado pelo uso abusivo do álcool e vivia uma decadência física e moral, que o havia conduzido a um isolamento e a um estado de marginalidade social, descobre-se agora igual a muitos outros com histórias e trajetórias semelhantes à sua. No interior do grupo, o alcoólico pode expor suas dores e narrar sua experiência sem ser estigmatizado e discriminado. Com isso, o alcoólico descobrese como fazendo parte de um "grupo de pares", que partilham de uma mesma ordem de significações, o que reforça, ao mesmo tempo, sua identificação como membro de AA e portador da doença "crônica e fatal" do alcoolismo.

De fato, os AA desempenharam um papel fundamental na sedimentação do conceito de "doença (disease) do alcoolismo" e seu tratamento 16. Eles têm mantido uma constante interação com a medicina - fato presente desde o surgimento da entidade -, pois um de seus co-fundadores era médico, e intensificado durante os trabalhos realizados pelo Yale Center of Alcohol Studies, conduzidos por E. M. Jellinek 17 juntamente com os AA nos anos 30 e 40, fundamentais na consolidação do alcoolismo entendido, ao mesmo tempo, como "doença" e "perda de controle" (loss of control) 8,18,19.

Analisando-se a literatura da entidade vêse que o alcoolismo é representado, inicialmente, como uma "doença progressiva e incurável”, resultado de uma articulação entre uma "sensibilidade física ao álcool" e "uma obsessão mental” por ingerir bebida alcoólica que impede o alcoólico de parar de beber.

É comum encontrarmos também a comparação entre o alcoolismo e o diabetes, de modo que o alcoólico apresenta uma espécie de "alergia ao álcool”. Assim, segundo os AA, é possível ser um alcoólico sem jamais ter bebido, bastando, para isso, não ter tido contato com a bebida alcoólica.

Como sublinha Fainzang 12, a teoria da doença elaborada pelos AA representa o alcoolismo a partir de uma "théorie de l'inné", própria a uma tradição biologizante largamente difundida nos Estados Unidos (local de origem dos AA). O alcoolismo é, portanto, representado como uma doença inata, de base "genética", enraizada no organismo do alcoólico. É visto também como uma "maladie de longue durée" 20; uma doença crônica de base orgânica e mental, que independe da "força de vontade" do alcoólico para sua superação e controle.

Como conseqüência, os AA desenvolvem uma teoria na qual o indivíduo não é responsável pela aquisição da doença alcoólica mas, ao contrário, a remete ao terreno da fatalidade e da aleatoriedade. A doença alcoólica é algo inato, inerente ao organismo do alcoólico, de modo que a doença independe tanto da vontade 
do indivíduo como da quantidade de álcool ingerida. Como sublinha M., membro do Escritório de Serviços Gerais de AA: "um alcoólico não se torna alcoólico: ele é alcoólico".

De acordo com os membros de AA, "uma vez que o alcoolismo tenha se fixado”, o indivíduo doente perde o "livre arbítrio", isto é, o doente alcoólico é incapaz de escolher se continua a beber ou não, tornando-se, então, "dependente” da bebida alcoólica. O estado de dependência se caracteriza, portanto, como a "perda de controle" (loss of control) sobre o álcool 19.

Nessa perspectiva, a teoria da doença dos AA não representa a doença alcoólica apenas com um problema orgânico e mental, mas também como uma doença que se articula à dimensão propriamente moral do indivíduo, constrangendo sua vontade, impedindo-o de agir de modo responsável. O alcoólico é, sobretudo, um dependente do álcool: não pode ser responsabilizado por sua doença.

Não por acaso, o AA também define o alcoolismo como uma "doença espiritual”: "o alcoolismo é, em nossa opinião, uma doença progressiva - espiritual e emocional (ou mental) tanto quanto física. Os alcoólicos que conhecemos parecem ter perdido o poder de controlar suas doses de bebidas alcoólicas” 21 (p. 4), que se liga à dimensão propriamente moral da vida do alcoólico.

A doença alcoólica definida, ao mesmo tempo, como uma "predisposição física aliada a uma obsessão mental" e como "doença espiritual” mobiliza representações - orgânicas e morais - que se referem tanto aos "limites mais restritos da pessoa” 22 (p. 144), chamando nossa atenção para o que se passa no plano intrapessoal, isto é, no indivíduo como totalidade "físico-espiritual", quanto como à sua repercussão no exterior, isto é, ao conjunto de relações sociais, nas quais o alcoólico está envolvido.

A teoria da doença envolve, portanto, representações que engajam os indivíduos em toda a sua complexidade físico-moral, apontando para as conexões e os fluxos que perpassam a dimensão física (corpórea), mental e espiritual, envolvendo o indivíduo em sua totalidade. Nesse sentido, o alcoolismo se manifesta tanto por meio da deterioração física (corpórea) do alcoólico, como pela deterioração das relações sociais, notadamente na família e no trabalho, comprometendo sua construção como "homem responsável”.

As narrativas colhidas durante a pesquisa de campo no grupo Sapopemba de AA são eloqüentes na representação do alcoolismo como uma doença que comporta uma multiplicidade de significados, os quais deslizam entre os planos físico e moral. Em seus relatos os membros do grupo mobilizam todo um leque de "categorias" para expressar suas aflições, compondo uma espécie de "nosografia profana" 23 da doença alcoólica. Trata-se de uma série de "sintomas" físicos/orgânicos, tais como: "tremores", “alergia”, “hipertensão”, “cirrose”, "ressaca”, “náuseas”, “delirium tremens”, “perda da memória” e, também, de uma rica quantidade de expressão de sintomas "morais", relacionados tanto ao "estado de espírito do alcoólico" como ao conjunto de relações sociais nas quais ele está envolvido, notadamente na "família" e no "trabalho": "egoísmo", "orgulho", “onipotência”, “ressentimento”, “perda dos amigos”, “perda da família”, "perda do trabalho”, "sarjeta moral", "sarjeta profissional" e "doença da família".

A teoria da doença estabelece uma conexão entre o âmbito físico e moral, que se articula à noção de dependência. O alcoolismo é, então, definido como um estado de dependência, que impede o alcoólico de escolher entre beber e não beber. Trata-se de uma dependência física do álcool que obriga o alcoólico a ingerir a bebida alcoólica. Esse estado de degradação física se expressa também por meio de sintomas, tais como "ânsias e dores de estômago" que, em geral, só passavam após a ingestão de bebida alcoólica: "eu acordava de manhã e sentia aquelas dores na barriga, no estômago; eu precisava vomitar e só depois que eu bebia aquilo passava (...). Eu comecei a ter ânsias às três horas da manhã, constantemente; mesmo se eu não tivesse bebido, vinha aquela ânsia. Me dava água na boca. Chegava oito e meia da manhã, não dava: e eu tinha que beber para ficar legal. Já tinha que beber. Eu já bebia de manhã mesmo. Eu era muito relaxado com meu físico".

Mas são, sobretudo, os tremores e as tremedeiras os sintomas mais característicos da dependência física: “Às vezes eu acordava de manhã tremendo, minhas mãos não paravam, e só depois que eu bebia é que eu melhorava".

Nota-se que o ato de beber deixou de ser um ato de vontade e de prazer e tornou-se uma necessidade física: “às vezes eu saia de casa e dizia para mim mesmo que eu não ia beber, mas de repente quando eu percebia, eu já estava com um copo na mão bebendo". Os tremores são, portanto, um signo de que o alcoólico está "refém do álcool”, isto é, dependente. Nas palavras de Fainzang 12 (p. 56), "o tremor da mão é estigmatizado como a expressão tangível de uma perda de controle de si mesmo e, por extensão, de uma dependência". A perda de controle (loss of control) sobre o álcool é narrada simbolizando o estado de dependência em que o al- 
coólico se encontra: "eu percebi que eu estava dependente do álcool quando tentei parar de beber e não consegui. Eu não conseguia dar sustentação a esse parar de beber".

Por outro lado, a dependência do álcool também impede o alcoólico de assumir suas "responsabilidades", notadamente em relação à família e ao trabalho. Nesse sentido, a doença alcoólica extravasa o limite intrapessoal, possibilitando a representação do alcoolismo como, por exemplo, uma “doença da família”. Nas palavras de P., secretário do grupo Sapopemba: "nós temos nossa terceira tradição que diz: 'para ser membro de AA o único requisito é o desejo de parar de beber'. Agora nem todos chegam ao AA com esse desejo de parar de beber. A maioria chega aqui forçado, porque a doença ela não é individual, a doença é da família, a doença é da coletividade. A doença é do indivíduo, só que afetando esse indivíduo ela afeta tudo”. Logo, para P., "a recuperação de um alcoólico significa também a recuperação da família”.

Nas palavras de um membro do grupo Sapopemba, pode-se vislumbrar uma descrição da doença alcoolismo que envolve o indivíduo em toda sua complexidade física e moral: "o alcoolismo me afetou principalmente na família $e$ no trabalho. Primeiro com a família, porque eu passei a ser aquele homem descompromissado; aquele homem com quem não se pode contar. Às vezes eu saía para fazer alguma coisa, mas quando tomava aquela primeira bebida, a segunda, a terceira, não tinha jeito. Isso me criou um problema muito sério, pois a própria família não acreditava mais em mim e eu também não. O alcoolismo me atrapalhava. A bebida passou a ser dona da minha vontade. Eu não tinha mais vontade própria. Embora eu não quisesse, mas ela me levava a beber. Aí eu perdia completamente a noção daquilo que eu queria fazer. Na fábrica foi a mesma coisa: eu tinha minhas atribuições junto aos demais companheiros mas, de acordo com minha bebedeira, ninguém podia contar comigo. Eu passei a ser um homem inútil na equipe. E aí eu sinto que eu mesmo perdi o domínio, perdi a credibilidade, eu perdi o interesse, eu perdi a força de vontade, eu perdi a força física".

Para os membros do grupo Sapopemba, o alcoolismo é representado, ao mesmo tempo, como a falência da "força física" e da "responsabilidade", constrangendo a vontade do indivíduo ("a bebida passou a ser dona da minha vontade. Eu não tinha mais vontade própria”), impedindo-o de assumir os papéis sociais de "pai", "esposo" e "trabalhador".

Grande parte da tematização do alcoolismo entre os membros de AA passa pela questão da responsabilidade. A relação entre o uso de bebidas alcoólicas e a questão da responsabilidade já havia sido levantada por Duarte 22, quando de sua análise do "nervoso" nas classes trabalhadoras urbanas e sua relação com o uso de bebidas alcoólicas, para apontar o papel ambíguo de que pode se revestir o uso do álcool para as classes trabalhadoras, o qual tanto pode ser um "estimulante" para trabalhos mais pesados quanto pode estar associado ao problema da "falência da responsabilidade" no cumprimento do dever 22.

Nesse quadro, a nossa pesquisa nota uma dupla conexão: a do efeito físico, representado pela deterioração e pelo enfraquecimento do organismo ("eu perdi a força física"), e a do efeito moral, visível na forma como esse enfraquecimento repercute sobre a totalidade da pessoa, fazendo brotar a irresponsabilidade nos territórios por excelência da responsabilidade, notadamente na família e no trabalho ("eu passei a ser aquele homem descompromissado"; " própria família não acreditava mais em mim”; "eu perdi a credibilidade"; "eu passei a ser um homem inútil na equipe”; "ninguém podia contar comigo”). Portanto, para os membros do grupo Sapopemba de AA, perder a força física significa, sobretudo, a perda da qualidade moral de prover a si mesmo e a família pelo trabalho. Com isso, o uso da bebida compromete, ao mesmo tempo, a vida física e moral do alcoólico, representada, particularmente, pela perda de suas qualidades morais e de suas responsabilidades, notadamente como "pai", "esposo" e "trabalhador".

É por isso que a estratégia terapêutica dos AA não visa apenas a abstinência de bebidas alcoólicas, mas visa, sobretudo, a manutenção da sobriedade do alcoólico, por meio da integração do doente numa nova ordem de sentido, que possibilita uma "unidade de experiência": "foi depois que eu descobri uma sala de AA e que o alcoolismo é uma doença que eu passei a dar um sentido à minha vida", dizem os membros de AA. O ex-bebedor pode, ao mesmo tempo, atribuir novos significados aos eventos vividos e modular a construção de sua identidade, isto é, reconhecer-se como indivíduo responsável tanto por sua recuperação como pelo provento de sua família e de seu trabalho.

Como conseqüência, o sistema de AA permite ao alcoólico (re)significar os espaços de sociabilidade, no interior dos quais constrói sua experiência, opondo, de um lado, o "bar", o "boteco", o "espaço da ativa", no qual as relações eram mediadas pelo uso de bebidas alcoólicas e, de outro, tanto o "grupo de AA", o "espaço da recuperação", como a "casa” e o "local 
de trabalho", espaços das relações familiares e profissionais, respectivamente, que são agora valorizados pelo "alcoólico em recuperação". Essa (re)significação dos espaços de sociabilidade fica clara no depoimento em que I. ressalta a importância de AA na sua recuperação e na mudança das relações com sua e mulher e seus filhos: “...antes de Alcoólicos Anônimos eu só pensava no bar. Quando chegava do trabalho, eu não parava cinco minutos em casa e já ia para o bar. Muitas vezes eu chegava em casa bêbado e nem tomava banho; dormia de qualquer jeito. Quando acordava era aquela ressaca (...). Hoje eu chego em casa, beijo meus filhos, converso com eles, com minha mulher. Agora, por exemplo, eu estou pagando a formatura de minha filha. Hoje, sóbrio, eu consigo conversar com meus filhos. Tudo isso eu devo ao Poder Superior e a Alcoólicos Anônimos".

Os AA, portanto, constroem uma estratégia terapêutica que possibilita a recuperação do alcoólico, por intermédio do resgate de sua responsabilidade, ao mesmo tempo física e moral. Assim, ao contrário da deterioração do organismo provocada pelo álcool, assiste-se agora a uma valorização da saúde e do bem-estar, expressa "no cuidado em fazer a barba", "cortar os cabelos", "tomar banho" e em "vestir-se".

O mesmo ocorre em relação ao âmbito moral: em vez do "orgulho", o alcoólico cultiva "humildade"; em vez do "egoísmo", ele cultiva o "altruísmo"; em lugar da "hostilidade”, ele cul- tiva a "amizade" e em lugar do "ressentimento", o alcoólico pratica a "ajuda" ao alcoólico que ainda sofre.

O alcoólico em recuperação (re)liga, portanto, os laços que foram rompidos no tempo do alcoolismo ativo. A estratégia terapêutica de AA possibilita que o alcoólico reconstrua os vínculos familiares e profissionais pelo cultivo de sua responsabilidade. Para os membros do grupo Sapopemba de AA, a responsabilidade não é uma categoria "ético-abstrata”, mas é a "responsabilidade-obrigação" para consigo mesmo e pelos atos cometidos nos tempos do alcoolismo ativo, sobretudo se esses atos provocaram danos a terceiros, que deverão, agora, ser reparados. À imagem do "homem descompromissado", "dependente do álcool" e que tem sua vontade dominada pela bebida, contrapõe-se a imagem do "homem responsável", membro de Alcoólicos Anônimos, que se responsabiliza pelo cuidado de si mesmo, ao mesmo tempo em que cumpre seus deveres em relação à sua família e ao seu trabalho.

Com a freqüência às suas reuniões e seguindo os passos de seu programa de recuperação, os AA constroem uma estratégia terapêutica que possibilita a seus membros participarem de uma efetiva cultura de recuperação, no interior da qual cuidam de si mesmos, ao mesmo tempo em que (re)significam suas experiências e reforçam seus laços, com o objetivo de alcançarem a sobriedade.

\section{Resumo}

O presente artigo tem por objetivo analisar as representações formuladas pelos membros da associação de ex-bebedores Alcoólicos Anônimos (AA) sobre o alcoolismo, com base nos resultados parciais de uma pesquisa qualitativa realizada no grupo Sapopemba de AA, em bairro da periferia da cidade de São Paulo, Brasil. Trata-se, portanto, de analisar o problema do alcoolismo a partir de uma perspectiva êmica, isto é, tal como ele é pensado e gerido por aqueles que se reconhecem como "doentes alcoólicos", como eles o explicam, o vivenciam e tentam superá-lo. Com isso busca-se apresentar a entidade dos AA e sua estratégia terapêutica, apontando-se a articulação que a entidade faz ao conceber o alcoolismo como doença físico-moral e espiritual.

Alcoólicos Anônimos; Alcoolismo; Grupos de AutoAjuda 


\section{Referências}

1. Institut National de la Santé et de la Recherche Médicale. Domages sociaux, abus et dépendance. Paris: Les Editions Inserm; 2003.

2. Centro Brasileiro de Informações sobre Drogas Psicotrópicas. I Levantamento Domiciliar Nacional sobre Uso de Drogas Psicotrópicas. São Paulo: Universidade Federal de São Paulo; 1999.

3. Alcoólicos Anônimos. O grupo de AA: onde tudo começa. São Paulo: Junta de Serviços Gerais de Alcoólicos Anônimos do Brasil; 2001.

4. Alcoólicos Anônimos. Os doze passos e as doze tradições. São Paulo: Junta de Serviços Gerais de Alcoólicos Anônimos do Brasil; 2001.

5. Gabhainn SN. Assessing sobriety and successful membership of Alcoholics Anonymous. J Subst Abuse 2003; 8:55-61.

6. Gilbert FS. Development of a "steps questionnaire". J Stud Alcohol 1991; 52:353-60.

7. Neves DP. Alcoolismo: acusação ou diagnóstico? Cad Saúde Pública 2004; 20:7-14.

8. Soares BM. Mulheres invisíveis: violência conjugal e novas políticas de segurança. Rio de Janeiro: Civilização Brasileira; 1999.

9. Barros LF. A alquimia dos grupos anônimos de auto-ajuda [Tese de Doutorado]. São Paulo: Faculdade de Educação, Universidade de São Paulo; 2001.

10. Garcia AM. "E o verbo (re) fez o homem": estudo do processo de conversão do alcoólico ativo em alcoólico passivo [Dissertação de Mestrado]. Rio de Janeiro: Programa de Pós-graduação em Antropologia e Ciência Política, Universidade Federal Fluminense; 2003.

11. Mota LA. A dádiva da sobriedade: a ajuda mútua nos grupos de alcoólicos anônimos. São Paulo: Paulus; 2004.
12. Fainzang S. Ethnologie des anciens alcooliques: la liberté ou la mort. Paris: PUF; 1996.

13. Alves PCB, Rabelo MC. Significação e metáforas na experiência da enfermidade. In: Rabelo MC, Alves PC, Souza IM, organizadores. Experiência da doença e narrativa. Rio de Janeiro: Editora Fiocruz; 1999. p. 171-85.

14. Mäkelä K. Alcoholics Anonymous: as mutual-help movement: un study in eight societies. Madison: University of Wisconsin Press; 1996.

15. Drulhe M. Mémoire et socialisation. Femmes alcooliques et associations d'anciens buveurs. Cahiers Internationaux de Sociologie 1988; 85: 313-24.

16. Yalisove D. The origins and evolution of the disease concept of treatment. J Stud Alcohol 1998, 59:469-75.

17. Jellinek EM. The disease concept of alcoholism. New Haven: Hilhouse Press; 1960.

18. Cerclé A. L'alcoolisme. Paris: Flammarion; 1998.

19. Levine HG. The discovery of addiction: changing conceptions of habitual drunkennes in America. J Stud Acohol 1978; 39:143-74.

20. Saliba C. La cure de désintoxication alcoolique et ses prolongements. Lyon: Press Universitaire de Lyon; 1982.

21. Alcoólicos Anônimos. Alcoólicos Anônimos em sua comunidade. São Paulo: Junta de Serviços Gerais de Alcoólicos Anônimos do Brasil; 2002.

22. Duarte LFD. Da vida nervosa da classe trabalhadora. Rio de Janeiro: Zahar; 1986.

23. Ancel P, Gaussot L. Alcool et alcoolisme: pratiques et representations. Paris: L'Harmattan; 1998.

Recebido em 02/Mar/2004

Versão final reapresentada em 17/Mai/2004

Aprovado em 31/Mai/2004 